\title{
STRATEGI BAURAN PEMASARAN 99ERS 100.0 FM DALAM MEMPERTAHANKAN RATING TOP RADIO REMAJA
}

\author{
Sheryl Vitridzky ${ }^{1}$ dan Itca Istia Wahyuni \\ ${ }^{1,2}$ Universitas Telkom
}

\begin{abstract}
ABSTRAK
Media massa radio pada saat ini begitu dibutuhkan oleh para pendengarnya, karena radio dapat didengarkan dimana saja dan kapan saja. Untuk radio segmentasi anak muda di kota Bandung tentu sangatlah banyak sehingga radio harus bersaing dengan para kompetitor untuk dapat mempertahankan rating yang dimilikinya. Oleh karena itu perlunya strategi bauran pemasaran (marketing mix) untuk mencapai tujuan yang diinginkan oleh radio terutama dalam mempertahankan rating radio segmentasi anak muda. Penelitian ini bertujuan untuk mendeskripsikan mengenai elemen bauran pemasaran jasa radio yang dikenal dengan 7P yaitu product, price, place, promotion, people, process dan physical evidence untuk mempertahankan top rating radio segmentasi anak muda. Penelitian ini menggunakan jenis penelitian kualitatif dengan metode deskriptif. Penulis memilih kasus Radio 99ers Bandung. Hasil penelitian yang telah dilakukan dapat disimpulkan berdasarkan masing-masing elemen bauran pemasaran. Produk yang dimiliki 99ers yaitu program dan konten siaran on air. Lokasi tempat yang sangat strategis karena di daerah Dago Bandung. Penentuan harga pada rate card menyesuaikan dengan klien. Promosi yang dilakukan yaitu advertising, public relations, word of mouth, event dan sponsorship. Partisipan yang sangat berperan banyak yaitu pendengar dan pengiklan. Proses yang dilakukan yaitu mengadakan meeting dan mengetahui jumlah pendengar setiap hari melalui web. Bukti fisik yang dimiliki yaitu id card, mobil operasional, alat programming, seragam, dan kantor.
\end{abstract}

Kata-kata Kunci: Strategi bauran pemasaran, 7p, bauran promosi, segmentasi, radio

\section{MARKETING MIX STRATEGY RADIO 99ERS TO MAINTAIN TOP RATING RADIO TEENAGERS SEGMENTATION}

\begin{abstract}
Media information is growing as time passes. In this age of the community is very actual and need information quickly. Radio's mass media at this time is so required by their listeners, because radio could in listen to wherever and anytime. For teenagers segmentation radio in the city of Bandung are necessary, so the radio should be compete with the competitors to able for maintain its rating available. Therefor needed a marketing mix strategy to achieve a desired goal by radio especially in maintaining rating teenagers segmentation radio. This research attempts to described about the elements marketing mix services radio known as $7 P$ the product, price, place, promotion, people, process and physical evidence to maintain top rating teenagers segmentation radio. This research using the kind of qualitative research with the descriptive methods. The Writer choose cases radio 99ers Bandung. The results of research has done can be concluded based on each element of mix marketing. The Products of 99ers are a Program and Broadcast on air content. Location which is very strategic because located in the area Dago Bandung. The price determination process in rate card adjust with clients. Promotion conducted are advertising, public relation, word of mouth, event and sponsorship. The Audience and advertisers are an important role participants. The process are held a meeting and knew the amount of listener everyday via web. The physical evidence are id card, the operational car, instrument programming, uniform, office.
\end{abstract}

Keywords: Marketing mix strategy, segmentasi,7Ps, promotion mix, radio

Korespondensi: Sheryl Vitridzky, S.Ikom. Program Studi Ilmu Komunikasi, Fakultas Komunikasi dan Bisnis, Universitas Telkom, Jl. Telekomunikasi Terusan Buah Batu, Bandung 40257. Email: vtrsheryl@, gmail.com 


\section{PENDAHULUAN}

Media informasi semakin berkembang seiring berjalannya waktu. Di zaman ini masyarakat tentunya sangat membutuhkan informasi yang aktual dan cepat. Dengan adanya media massa tentu saja akan mempermudah masyarakat untuk mendapatkan informasi. Untuk radio segmentasi anak muda di kota Bandung tentu sangatlah banyak sehingga radio harus bersaing dengan para kompetitor untuk dapat mempertahankan rating yang dimilikinya. Oleh karena itu perlunya strategi bauran pemasaran (marketing mix) untuk mencapai tujuan yang diinginkan oleh radio terutama dalam mempertahankan rating radio segmentasi anak muda. Penelitian ini bertujuan untuk mendeskripsikan mengenai elemen bauran pemasaran jasa radio yang dikenal dengan 7P yaitu product, price, place, promotion, people, process dan physical evidence untuk mempertahankan top rating radio segmentasi anak muda.

Hasil temuan Nielsen Radio Audience Measurement pada kuartal ketiga tahun 2016 menunjukkan bahwa $57 \%$ dari total pendengar radio berasal dari Generasi Z yaitu anak-anak yang terlahir mulai 1990 atau sesudah 1994 yang hidup di masa digital dan Millenials. Saat ini 4 dari 10 orang pendengar radio mendengarkan radio melalui perangkat yang lebih personal yaitu mobile phone. Nielsen Radio Audience Measurement mencatat bahwa meskipun internet tumbuh pesat pada kuartal ini, tidak berarti bahwa jangkauan akan pendengar radio menjadi rendah. Kendati penetrasi media televisi (96\%), Media Luar Ruang (52\%) dan Internet (40\%) masih tinggi namun media radio masih terbilang cukup baik di angka 38 persen pada kuartal ketiga 2016 ini. Temuan Nielsen Radio Audio Measurement kuartal ini menunjukkan bahwa tingkat penetrasi Radio pada konsumen, tertinggi berada di kota Palembang dengan 97 persen, disusul oleh pendengar di kota Makassar dengan 60\%, Bandung (54\%), Banjarmasin $(53 \%)$ dan Yogyakarta (51\%). Radio tidak lagi didengarkan melalui radio tape saja, tetapi kini perilaku pendengar telah berubah menjadi mengedepankan teknologi dan fleksibilitas dalam mendengarkan radio. Radio kini berangkat menjadi media yang lebih personal bagi masing-masing konsumen. Tiga kota terbesar dari konsumen yang mendengarkan radio dari perangkat mobile mereka berada di kota Makassar (69\%), Medan (44\%) dan Jakarta (38\%) (Nielsen, 2016).

Keunggulan radio dibandingkan media lainnya yaitu setiap orang bisa mendengarkan radio kapan saja dan dimana saja tanpa harus meluangkan waktunya untuk mendengarkan informasi. Bahkan saat ini radio tidak hanya bisa didengarkan melalui radio tape saja, tetapi kini radio sudah bisa didengarkan melalui mobile phone. Hal ini lebih efektif dibandingkan harus selalu mendengarkan melalui radio tape. Teknologi yang semakin canggih maka mengedepankan fleksibilitas dalam mendengarkan radio.

Dari sekian banyak stasiun radio, 99ers merupakan salah satu radio yang berada di kota Bandung, radio 99ers 100.0 FM yaitu radio yang segmentasinya adalah anak muda yang memiliki konsistensi terhadap pendengarnya bahwa pendengarnya adalah segmentasi anak muda. Dengan adanya segmentasi tersebut maka radio 99ers harus mempertahankan para pendengar yang segmentasi nya anak muda. Maka dengan elemen bauran pemasaran jasa yaitu 7P product, price, place, promotion, people, process, physical evidence 99ers harus mampu menarik para pendengar untuk menjadi pendengar setia radio 99ers. Secara keseluruhan radio yang segmentasinya anak muda maka ada beberapa radio lainnya seperti Ardan, Oz, 99ers, Urban, Hitz, Paramuda (hasil wawancara dengan Ramadhan 99ers. Rabu, 16 November 2016 pukul 16:30).

Tepat satu setengah tahun 99ers Radio mengudara, 99ers Radio berhasil mencapai posisi puncak rating radio anak muda no.1, yaitu segmen pendengar 15-24 AB dan ke-5 all segmen di survei AC Nielsen 2001. Pada survei AC Nielsen 2004, 2005, 2006, 2007, 2009, 2010, 2011, 2012 99ers Radio tetap bertahan di posisi atas sebagai radio anak muda Bandung no.1. Untuk 7 tahun berturut-turut, 99ers radio menempati posisi radio anak muda (15-24 \& 15-24 AB) No. 1 di Bandung dalam survei 
AC Nielsen 2010 sebagai radio yang paling tajam dan konsisten pada segmennya (hasil wawancara dengan Ramadhan 99ers. Rabu, 16 November 2016 pukul 16.15).

Pemasaran adalah kegiatan menganalisis, mengorganisasi, merencanakan, dan mengawasi sumber daya, kebijaksanaan, serta kegiatan yang menimpa para pelanggan perusahaan dengan maksud memuaskan kebutuhan dan keinginan para kelompok pelanggan yang terpilih untuk memperoleh laba (Philip Kotler, 1967: 12). perkembangan mengenai arti pemasaran berikutnya mengarah pada pencarian cara untuk memuaskan kebutuhan dan keinginan para pelanggan dengan melakukan penelitian dan analisis kebutuhan serta keinginan calon pelanggan, bukan hanya cara menjual barang atau jasa. Dengan demikian, fokus kegiatan pemasaran adalah menemukan caracara bagaimana seorang pemasar (marketer) mengatur usaha pemasarannya supaya mampu memenuhi kebutuhan dan keinginan manusia umumnya, khususnya kebutuhan dan keinginan kelompok masyarakat dengan ciri-ciri tertentu yang dilihat dari faktor pekerjaan, penghasilan, dan gaya hidupnya, atau dengan kata lain, dari segmen masyarakat tertentu.

Radio 99ers perlu menggunakan beberapa elemen bauran pemasaran untuk memasarkan 99ers agar semakin banyak para pendengarnya dan nama 99ers akan semakin dikenal di kalangan anak muda terutama di Kota Bandung. Elemen bauran pemasaran yang harus digunakan yaitu seperti product, people, price, place, promotion, process, physical evidence. Maka apabila 99ers melakukan beberapa dari elemen bauran pemasaran tersebut maka akan berpengaruh kepada peningkatan rating top radio dan mempertahankan rating top radio yang sudah ada.

99ers untuk mempertahankan para listeners maka di waktu On air atau Off air prime time 99ers perlu mengadakan program-program yang menarik. Karena konten radio menjadi salah satu tombak agar para pendengar 99ers akan selalu setia mendengarkan program-program yang disiarkan, program siaran tersebut tidak membosankan untuk didengar maka konten program harus dibuat semenarik mungkin. 99ers sudah mempunyai beberapa program rutin pada waktu prime time jam 6-8 Pagi dan jam 4-8 Malam. Seperti Sarapan Pagi, Let's Play 99ers, dan masih banyak lagi program lainnya yang disiarkan setiap harinya. Oleh karena itu apabila 99ers ingin mempertahankan para pendengar dengan segmentasi anak muda maka 99ers harus selalu mengembangkan dan menyajikan program-program terbaik untuk memahami apa yang diinginkan oleh listeners.

Merujuk kepada pemaparan latar belakang, penulis akan melakukan kajian secara mendalam mengenai bagaimana strategi marketing mix yang dilakukan oleh Radio 99ers FM 100.0 Bandung sebagai media partner yang dipilih oleh para pengiklan serta bagaimana 99ers untuk mempertahankan top radio No.1 di Bandung dengan segmentasi anak muda. Oleh karena itu, penulis merumuskan judul yaitu "Strategi Bauran Pemasaran Radio 99ers 100.0 FM dalam Mempertahankan Rating Top Radio Segmentasi Anak Muda".Merujuk pada latar belakang penulisan, fokus penelitian yaitu "Bagaimana Strategi Bauran Pemasaran Radio 99ers 100.0 FM dalam Mempertahankan Rating Radio Terpopuler dengan Segmentasi Anak Muda di Kota Bandung".

Ada berbagai definisi yang dikemukakan oleh para ahli mengenai pemasaran (Ari, Jusuf \& Efendi, 2015: 6-7). Pada Tahun 1960, American Marketing Association (AMA) telah menyatakan definisi pemasaran sebagai berikut: "Pemasaran adalah kinerja dari kegiatan bisnis yang mengarahkan arus barang dan jasa kepada para pelanggan dan pemakai."

Selain AMA, Philip Kotler (dalam Reza 2016: 66), mendefinisikan pemasaran sebagai berikut: Pemasaran adalah kegiatan menganalisis, mengorganisasi, merencanakan, dan mengawasi sumber daya, kebijaksanaan, serta kegiatan yang menimpa para pelanggan perusahaan dengan maksud memuaskan kebutuhan dan keinginan para kelompok pelanggan yang terpilih untuk memperoleh laba.

Cara seorang pemasar melaksanakan tugasnya memasarkan produk dapat disebut usaha untuk mengelola kegiatan pemasaran atau manajemen pemasaran. Manajemen pemasaran 


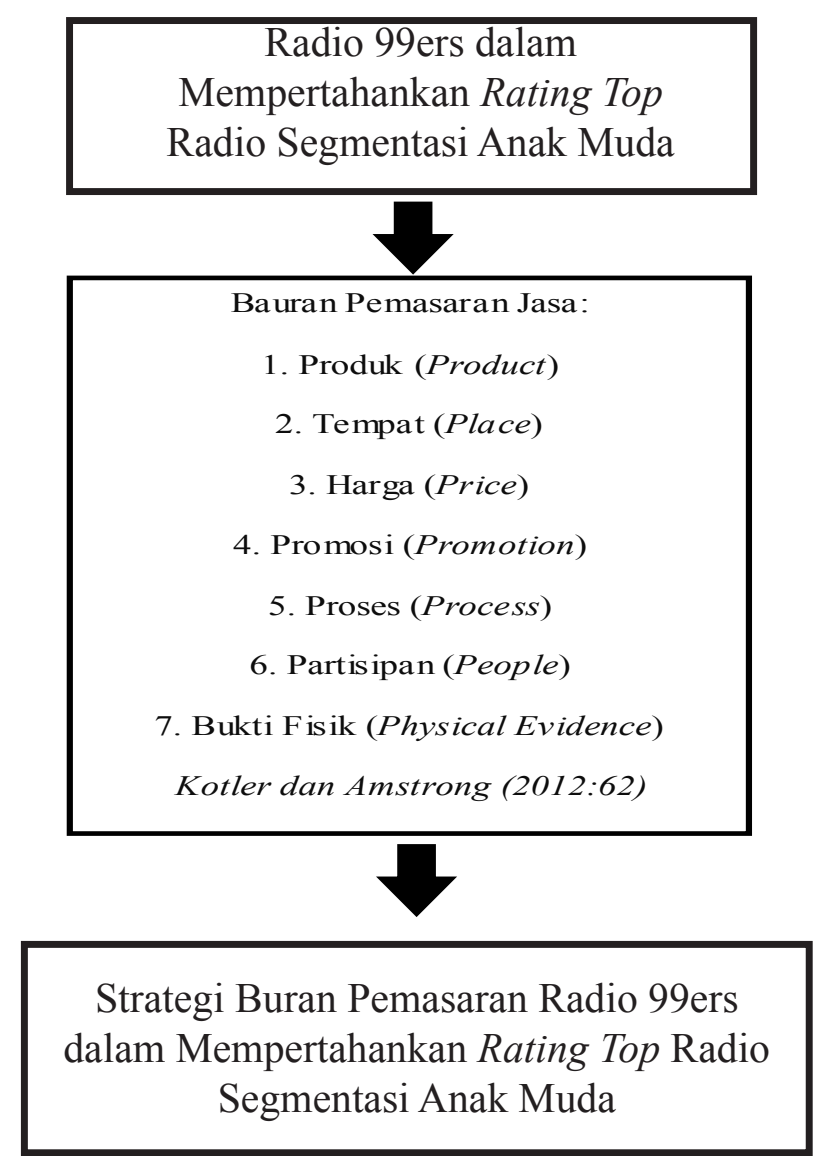

Sumber: Hasil Olahan Peneliti, 2016

\section{Gambar 1 Kerangka Pemikiran}

mencakup cara menciptakan dan melaksanakan putusan-putusan untuk memasarkan gagasan spesifik, barang, dan jasa (Ari, Jusuf \& Efendi, 2015: 11). Bauran pemasaran merupakan satu dari sekian konsep yang paling universal yang telah dikembangkan dalam pemasaran. (Adrian, 2000: 28) Kebanyakan pembahasan mengenai pemasaran memusatkan perhatian sekitar empat komponen kunci bauran pemasaran, yang disebut 4P. Komponen ini meliputi: product, price, promotion, dan place.

Booms dan Bitner (1980), menawarkan konsep 7P (product, price, place, promotion, participants, physical evidence, process) sebagai pengganti 4P. Kotler (2003), menambah 2P, yaitu political power dan public opinion sehingga menjadi $6 \mathrm{P}$.

Jasa (service) adalah aktivitas atau manfaat yang ditawarkan oleh satu pihak kepada pihak lain yang pada dasarnya tanpa wujud dan tidak menghasilkan kepemilikan apapun. (Philip Kotler, 2003: 276). Jasa (service) adalah sebuah bentuk produk yang terdiri atas berbagai kegiatan, keuntungan-keuntungan (benefits) atau kepuasan yang ditawarkan untuk dijual dan pada dasarnya tidak berwujud (intangible) serta tidak berakibat pada kepemilikan atas sesuatu, seperti kegiatan perbankan, layanan hotel, perjalanan udara, perusahaan ritel, bengkel reparasi, dan salon kecantikan. (Ari, Jusuf \& Efendi, 2015: 92-93).

Produk dibagi menjadi dua, yaitu barang dan jasa. Barang adalah produk yang berwujud, seperti pakaian, makanan, dan mainan anakanak. Di sisi lain, jasa adalah aksi, kinerja, dan pengalaman yang ditawarkan oleh satu pihak kepada pihak lain (McColl-Kennedy, 2003). Bauran pemasaran memiliki 4 elemen yaitu product, price, place, dan promotion. Namun untuk bauran pemasaran jasa di perluas agar lebih tepat 7P yaitu people, process, dan physical evidence. Hasilnya, 4P tradisional diperluas dan ditambahkan dengan empat unsur lainnya, yaitu people, process, physical evidence, dan customer service. Keputusan mengenai setiap unsur bauran pemasaran ini saling berkaitan 
satu sama lain. Kendati demikian, tingkat kepentingan yang ditekankan pada masingmasing unsur cenderung bervariasi antar jasa. (Tjiptono, 2014: 42-44).

\section{METODE PENELITIAN}

Penelitian ini menggunakan penelitian kualitatif dan diarahkan oleh paradigma yang digunakan. Paradigma yang digunakan dalam penelitian ini adalah post positivisme. Dapat dikatakan bahwa post-positivisme sebagai reaksi terhadap positivisme. Menurut pandangan postpositivisme, kebenaran tidak hanya satu tetapi lebih kompleks, sehingga tidak dapat diikat oleh satu teori tertentu saja (Yanuar, 2012: 71).

Penelitian ini menggunakan metode penelitian deskriptif kualitatif. Dalam pengumpulan data, metode ini menggunakan teknik wawancara, dengan menggunakan schedule questionnair ataupun interview guide (wawancara terstruktur) (Nazir, 1989: 64).

Sementara Sugiyono dalam bukunya Metode Penelitian Kuantitatif, Kualitatif dan $\mathrm{R}$ \& D menyebutkan empat teknik dalam pengumpulan data kualitatif, yakni: observasi, wawancara, dokumentasi, dan gabungan/ triangulasi (Sugiyono, 2013: 225). Penelitian ini menggunakan teknik pengumpulan data wawancara dan analisis dokumen.

Menurut Bogdan \& Biklen, analisis data kualitatif adalah upaya yang dilakukan dengan jalan bekerja dengan data, mengorganisasikan data, memilah-milahnya menjadi satuan yang dapat dikelola, mensistensiskannya, mencari dan menemukan pola, menemukan apa yang penting dan apa yang dipelajari, dan memutuskan apa yang dapat diceritakan kepada orang lain (dikutip dalam Moleong, 2006: 248).

Subjek penelitian merupakan siapa saja yang akan diteliti dalam penelitian ini. Dalam penelitian ini yang akan dijadikan subjek penelitian adalah beberapa karyawan 99ers yang bergerak pada bidang IT/Teknologi dan marketing untuk memberikan informasi dan saran terhadap penelitian ini. Karena mereka yang bergerak pada bidang IT akan membantu mencari data mengenai rating Radio 99ers dan data pendengar Radio 99ers, serta yang bergerak pada bidang marketing akan memberikan informasi mengenai bauran pemasaran di bidang marketing yang dilakukan oleh 99ers.

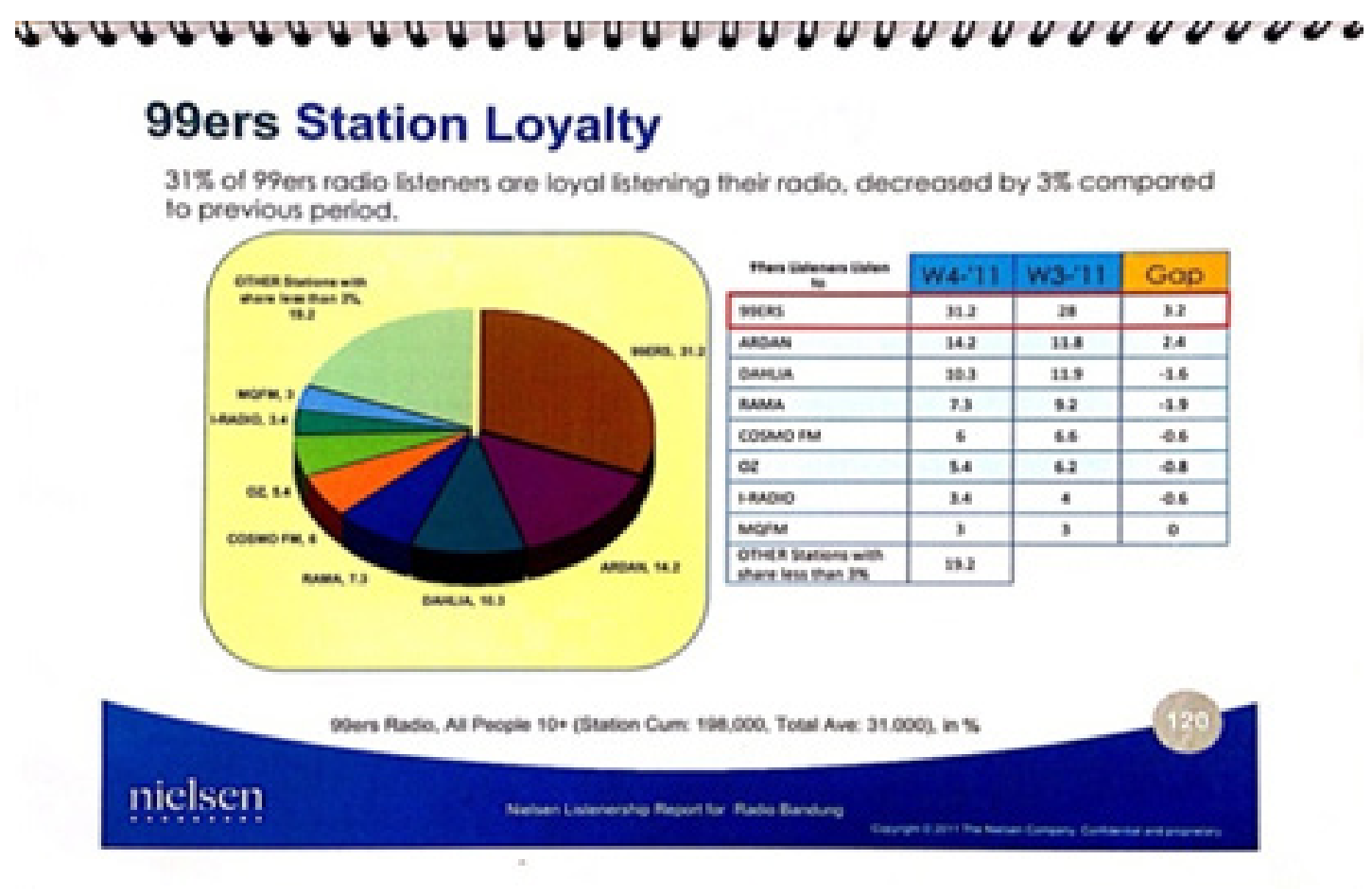

Sumber: AC Nielsen

Gambar 2 Data 99ers Station Loyalty 2011 
Objek penelitian yang akan diteliti yaitu strategi bauran pemasaran 99ers dalam mempertahankan rating top radio segmentasi anak muda di Kota Bandung. Peneliti ingin meneliti dan mengetahui bagaimana strategi bauran pemasaran yang dilakukan oleh Radio 99ers yaitu merupakan media massa radio yang selalu menyajikan informasi serta hiburan untuk masyarakat terutama yang segmentasinya anak muda di Kota Bandung. Radio 99ers yang sudah terkenal sejak tahun 1999 selalu memenuhi kebutuhan para pendengarnya dengan membuat program-program yang membuat anak muda menarik, oleh karena itu radio 99ers menjadi top radio segmentasi anak muda di Kota Bandung.

Bungin dalam bukunya Metodologi Penelitian Sosial dan Ekonomi menulis sedikitnya enam teknik pengumpulan data dalam penelitian kualitatif, yakni: observasi partisipasi, wawancara mendalam, life history, analisis dokumen, catatan harian peneliti, dan analisis media (Bungin, 2013: 173). Diantara teknik pengumpulan data yang lazim digunakan dalam penelitian kualitatif menurut penulis adalah, observasi, wawancara, dokumentasi, dan focus group discussion.

Menurut Bogdan \& Biklen (1982), analisis data kualitatif adalah upaya yang dilakukan dengan jalan bekerja dengan data, mengorganisasikan data, memilahmilahnya menjadi satuan yang dapat dikelola, mensistesiskan, mencari dan menemukan pola, menemukan apa yang penting dan apa yang dipelajari, dan memutuskan apa yang dapat diceritakan kepada orang lain (dikutip dalam Moleong, 2006: 248).

Menurut Patton (1980), analisis data kualitatif adalah suatu proses mengatur urutan data, mengorganisasikannya ke dalam suatu pola, kategori, dan satuan uraian dasar, hingga proses penafsiran. Dalam konteks analisis, penafsiran dimaksud yaitu memberikan arti yang signifikan terhadap analisis, menjelaskan pola uraian, dan mencari hubungan diantara dimensi-dimensi uraian (lihat dalam Kaelan, 2012: 130).

Cara meningkatkan kepercayaan penelitian adalah dengan mencari data dari sumber yang beragam yang masih terkait satu sama lain.
Peneliti perlu melakukan eksplorasi untuk mengecek kebenaran data dari beragam sumber. (Djam'an Satori \& Aan Komariah, 2011: 170).

\section{HASIL DAN PEMBAHASAN}

Dari berbagai sumber yang didapatkan dari ke 4 informan, didapatkan hasil bahwa menurut 99ers radio mereka merupakan sudah mencapai tujuan dalam membuat program untuk mempertahankan top rating radio segmentasi anak muda tersebut. Namun menurut expertise bahwa rating top radio hanya bisa dinilai oleh AC Nielsen, serta program yang dibuat harus sesuai dengan "Needs and wants"-nya. Karena menurut expertise program yang dibuat oleh 99ers masih relatif sama dengan radio segmentasi anak muda lainnya di kota Bandung.

Jadi menurut data yang dimiliki oleh Radio 99ers dari AC Nielsen bahwa pada tahun 2011 99ers mendapat peringkat pertama untuk kategori pendengar setia terbanyak. Karena memang strategi pemasaran yang dilakukan oleh Radio 99ers yaitu memahami kebutuhan pendengar segmentasi anak muda dalam membuat program. Maka hasil riset AC Nielsen kategori pendengar setia Radio 99ers menduduki peringkat pertama.

Hasil dari wawancara dengan berbagai sumber informan, didapatkan hasil bahwa rate card yang sudah ditetapkan oleh Radio 99ers menyesuaikan juga dengan keinginan para klien karena walaupun harga sudah ditetapkan pada rate card namun masih saja ada agency atau klien yang melakukan tawar-menawar harga untuk memasang iklan di Radio 99ers.

Hasil yang dari keseluruhan wawancara dengan informan radio 99ers sudah melakukan promosi yang dapat meningkatkan brand yang dimiliki oleh radio 99ers, sehingga promosi yang dilakukan dapat meningkatkan atau mempertahankan rating radio 99ers. Hasil yang didapatkan dari berbagai sumber informan yaitu 99ers telah melakukan proses seperti evaluasi dengan meeting lalu mengecek rating atau jumlah pendengar dengan menggunakkan web pribadi yang dimiliki oleh 99ers, lalu melakukan strategi marketing untuk mempertahankan atau bahkan meningkatkan rating yang dimiliki. 
Namun menurut pendapat expertise proses yang dilakukan dalam melakukan langkah strategi marketing hal tersebut akan menjadi nilai tambah untuk mempertahankan rating dan pendengarnya.

Dari hasil wawancara tersebut didapatkan kesimpulan bahwa lokasi kantor Radio 99ers sudah cukup strategis walaupun masih ada beberapa kekurangan karena lokasi kantor yang berada di dalam dan tidak dapat langsung dilihat oleh para pengunjung yang akan datang. Partisipan atau orang yang terlibat dalam bisnis perusahaan baik produk maupun jasa tentunya sangat berpengaruh pada perusahaan. Seperti Radio 99ers yang memiliki partisipan pendengar dan pengiklan yang dapat mampu mengembangkan bisnis dalam bidang jasa menjadi lebih baik lagi.

Dalam mempertahankan rating top radio segmentasi anak muda tentu saja perlu penilaian dari para pendengar ataupun pengiklan untuk 99ers. Maka dari itu peran pendengar dan pengiklan sangatlah berpengaruh besar terhadap Radio 99ers untuk mempertahankan rating nya.

Dari hasil wawancara yang didapatkan mengenai bukti fisik yang dimiliki oleh Radio 99ers sudah cukup lengkap untuk memenuhi kebutuhannya melakukan siaran on air maupun off air. Dari hasil wawancara dapat disimpulkan bahwa radio 99ers telah membuat dan mengemas produk nya sebaik mungkin dalam bisnisnya. Radio 99ers menjual produk nya melalui konten program yang disiarkan melalui on air. Selain itu radio 99ers juga memiliki program off air untuk melengkapi kebutuhan para pendengarnya dengan membuat acara 9coustic sebagai acara rutin bulanan 99ers. Program on air yang dimiliki Radio 99ers yaitu seperti Sarapan Pagi, Let's Play 99ers, Good Afternoon, Pulang Sore, The Good Night Show, Rest Area, AADC, Movie Station, Kamar Gaby, Buka Mata, Play FC, Cozy Weekend, Minggu Baru, Mixing Hours, Saturdate, Tempoe Doloe, Special Mixtape, BoogieNight, dan EasySunday. Dari beberapa program yang disebutkan ada beberapa program favorit seperti Sarapan Pagi, Let's Play 99ers, Good Afternoon, dan Pulang Sore karena program tersebut memutarkan lagu-lagu yang sedang hits di kalangan anak muda serta mengadakan request lagu. Serta ada program menarik seperti Kamar Gaby, AADC, Buka Mata, dan Tempoe Doloe.

Selain itu di hari tertentu seperti hari Rabu biasanya 99ers mengundang bintang tamu seperti komunitas foodtruck atau selebgram. 99ers juga pernah siaran langsung di kafe-kafe yang bekerja sama dengan 99ers, lalu program Uji Teror setiap malam Jumat yaitu Uji Tempat Horor dengan mengunjungi tempat-tempat horor dan langsung siaran di tempat horor tersebut sambil medeskripsikan apa yang dirasakan saat berada di tempat horor tersebut. Jadi dari seluruh produk yang dimiliki radio 99ers sudah cukup baik untuk mempertahankan rating top radio segmentasi anak muda. Walaupun menurut expertise program tersebut masih sama saja seperti program radio kompetitor lainnya yang segmentasinya anak muda.

Selain itu sudah sesuai dengan teori produk yang ada pada buku Pemasaran Jasa Fandy Tjiptono bahwa produk merupakan penawaran untuk mencapai tujuan organisasi melalui pemuasan kebutuhan dan keinginan pelanggan. Radio 99ers telah melakukan hal tersebut dalam membuat program yang disiarkan dengan lebih menyesuaikan kebutuhan pendengarnya dibandingkan dengan keinginan 99ers untuk membuat program siaran.

Dari hasil wawancara dapat disimpulkan bahwa harga yang ditetapkan pada rate card radio 99ers sudah cukup terjangkau. Karena 99ers dapat menyesuaikan dengan rating serta keinginan para klien. Karena permintaan para klien berbeda-beda sesuai budget yang dimilikinya. Kliennya antara lain yaitu perusahaan, EO, dan mahasiswa.

Radio 99ers juga membuat sistem full barter dan semi barter bahkan gratis untuk acara-acara yang sekiranya dapat memberikan feedback yang baik untuk Radio 99ers. Misalnya apabila bekerja sama menjadi media partner dengan suatu event lalu di dalam event tersebut mengundang artis papan atas yang terkenal maka radio 99ers dapat memberikan gratis untuk mempromosikan event tersebut melalui radio 99ers. Lalu apabila full barter dan semi barter yaitu contohnya seperti misalnya 99ers bekerja sama dengan Berrybenka dalam 
memasang iklan.

Total harga pemasangan iklan yaitu sebesar 2 juta rupiah. Namun Berrybenka ingin melakukan full barter dengan tiket belanja di Berrybenka seharga 2 juta rupiah sesuai dengan total pemasangan iklan, lalu apabila semi barter misalnya total pemasangan iklan sebesar 2 juta rupiah tetapi Berrybenka hanya membayar dengan uang tunai sebesar 1 juta rupiah sedangkan 1 juta rupiah lagi dengan tiket belanja di Berrybenka itu disebut sistem semi barter. Lalu dengan harga yang ditetapkan pada rate card 99ers memiliki perbedaan harga dengan radio lain kisaran 200 hingga 400ribu rupiah baik lebih murah atau lebih mahal tergantung rating radio kompetitornya. Maka dari itu sesuai dengan teori yang sudah disampaikan mengenai price di dalam buku Fandy Tjipnono bahwa keputusan bauran harga berkenaan dengan kebijakan strategik dan taktikal, seperti tingkat harga, struktur diskon, syarat pembayaran, dan tingkat diskriminasi harga di antara berbagai kelompok pelanggan.

Dari hasil wawancara dengan para sumber informan maka sesuai dengan teori yang dikatakan oleh Hamdani dan buku yang dibuat oleh Yudi Pramudiana, yaitu bauran promosi menurut Hamdani (2006: 160-161) meliputi periklanan (advertising), penjualan perseorangan (personal selling), promosi penjualan (sales promotion), hubungan masyarakat (public relations), informasi dari mulut ke mulut (word of mouth), pemasaran langsung (direct marketing). Kegiatan lain yang dapat dilakukan dalam komunikasi pemasaran adalah Event dan Sponsorship (Pramudiana, dkk, 2015: 123). Dari beberapa bauran promosi yang disebutkan Radio 99ers telah melakukan bauran promosi seperti periklanan, hubungan masyarakat, word of mouth, event dan sponsorship.

Dari hasil wawancara dapat disimpulkan bahwa Radio 99ers telah melakukan proses agar Radio 99ers dapat mempertahankan rating top radio segmentasi anak muda, sesuai dengan teori yang ada pada buku karangan Fandy Tjiptono (2014: 43) bahwa proses produksi atau operasi merupakan faktor penting bagi konsumen highcontact service, yang kerap kali juga berperan sebagai co-producer jasa bersangkutan.

Dari hasil wawancara dapat disimpulkan bahwa sesuai dengan teori yang ada pada buku karangan (Tjiptono, 2014: 43) yang menjelaskan bahwa keputusan distribusi menyangkut kemudahan akses terhadap jasa bagi para pelanggan potensial. Keputusan ini meliputi keputusan lokasi fisik (misalnya keputusan mengenai di mana sebuah hotel atau restoran harus didirikan), keputusan mengenai penggunaan perantara untuk meningkatkan aksesibilitas jasa bagi para pelanggan.

Rachamawati mengemukakan Pemasaran lebih dipandang sebagai seni daripada ilmu, maka seorang ahli pemasaran tergantung pada lebih banyak pada keterampilan pertimbangan dalam membuat kebijakan daripada berorientasi pada ilmu tertentu. Pandangan ahli ekonomi terhadap pemasaran adalah dalam menciptakan waktu, tempat dimana produk diperlukan atau diinginkan lalu menyerahkan produk tersebut untuk memuaskan kebutuhan dan keinginan konsumen konsep pemasaran (Rachmawati, 2011).

Lokasi yang dipilih oleh radio 99ers sebagai kantornya yaitu di Jl. Ir. H. Djuanda 126 B Bandung (Dago). Sebelumnya lokasi kantor radio 99ers yaitu di BRI Tower daerah Asia Afrika. Lokasi kantor radio 99ers saat ini sudah cukup strategis karena aksesnya yang mudah dan Dago merupakan pusat kota yang terkenal di kota Bandung. Maka apabila ada klien atau siapapun yang ingin mengunjungi lokasi kantor maka dengan mudah dapat dijangkau karena lokasi kantor saat ini cukup strategis dan dapat mempengaruhi rating dalam mempertahankan radio segmentasi anak muda tersebut.

Menurut buku Pemasaran Jasa. Bagi sebagian besar jasa, orang merupakan unsur vital dalam bauran pemasaran. (Tjiptono, 2014: 43) maka sesuai dengan hasil penelitian ini yang mengkaitkan teori tersebut dengan hasil penelitian.

Dari hasil wawancara dapat disimpulkan bahwa partisipan sangat berpengaruh terhadap pengembangan pemasaran jasa. Misalnya pada hasil penelitian ini bahwa peran partisipan seperti pendengar dan pengiklan sangat berpengaruh besar terhadap radio 99ers untuk 
mempertahankan rating nya tersebut. Karena peran pendengar sangat berpengaruh terhadap keberhasilan sebuah radio, apabila tidak ada pendengar radio tersebut bukanlah apa-apa.

Peran pengiklan sangat berpengaruh pada kebutuhan finansial radio yang dapat membuat radio tersebut dapat mempertahankan rating dengan menggunakan finansial sebagai alat untuk promosi. Jadi peran keduanya sangatlah berpengaruh baik. Oleh karena itu seorang expertise mengatakan bahwa keduanya termasuk pada hukum kausalitas atau sebab akibat. Serta sesuai dengan teori yang ada dikatakan oleh Fandy Tjiptono bahwa orang merupakan unsur vital dalam bauran pemasaran.

Dari hasil keseluruhan wawancara tersebut maka sesuai dengan teori yang ada pada buku karangan (Fandy Tjiptono, 2014: 43) yaitu salah satu unsur penting dalam bauran pemasaran adalah upaya mengurangi tingkat risiko tersebut dengan jalan menawarkan bukti fisik dari karakteristik jasa. Bukti fisik ini bisa dalam berbagai bentuk, misalnya penampilan staf yang rapi dan sopan, alat-alat rekaman untuk siaran radio yang lengkap, ruangan yang nyaman.

Menurut Selang, bauran pemasaran adalah satu perangkat yang terdiri dari produk, harga, promosi dan distribusi, yang didalamnya akan menentukan tingkat keberhasilan pemasaran dan semua itu ditujukan untuk mendapatkan respons yang diinginkan dari pasar sasaran. Loyalitas pelanggan adalah hasil yang didapat dari satu organisasi yang menciptakan manfaat kepada pelanggannya, sehingga mereka akan tetap melakukan pembelian dan bahkan meningkatkan pembelian dari organisasi tersebut (Selang, 2013).

Dari hasil wawancara dapat disimpulkan bahwa radio 99ers memiliki beberapa bukti fisik yaitu seperti alat programming, OB van atau mobil operasional, seragam, id card, mixer, alat band, software, comrex, piala penghargaan, kantor, dan masih banyak lagi yang lainnya. Bukti fisik tersebut guna untuk melengkapi kebutuhan dalam melakukan siaran atau bahkan mempertahankan rating radio 99ers. Karena dengan adanya bukti fisik maka klien atau orang lain pun akan semakin percaya bahwa radio 99ers merupakan radio yang mempunyai kelengkapan yang cukup sebagai top radio di kota Bandung ini dengan segmentasi anak muda. Putra, Yulianto, \& Sunarti (2015) mengemukakan perilaku konsumen dapat didefinisikan sebagai tindakan-tindakan atau perilaku dan hubungan sosial yang dilakukan oleh konsumen, kelompok maupun suatu organisasi untuk menilai, memperoleh dan menggunakan barang-barang serta jasa melalui sebuah proses pertukaran atau pembelian yang diawali dengan proses pengambilan keputusan.

\section{SIMPULAN}

Berdasarkan seluruh uraian dalam Hasil dan Pembahasan, maka dapat ditarik kesimpulan sebagai berikut: Radio 99ers 100.0 FM Bandung telah melakukan strategi pemasaran 7P dengan cukup baik untuk mempertahankan top rating radio segmentasi anak muda. $7 \mathrm{P}$ tersebut meliputi product, price, promotion, process, place, people, physical evidence. Produk yang dibuat oleh radio 99ers dalam mempertahankan rating yaitu dengan membuat program on air dan off air yang memiliki konten yang menarik dan unik untuk para pendengar yang segmentasinya anak muda. Terutama pada program andalan mereka yaitu Sarapan Pagi, Good Afternoon, dan Pulang Sore.

Pada kategori entertainment memiliki persentase $50 \%$, informatif $30 \%$, dan edukatif $20 \%$. Dengan segmentasi pendengar yaitu usia 15-24 tahun. Jadi radio 99ers sangat konsisten dalam membuat program untuk segmentasinya dari dulu adalah anak muda. Dalam menentukan harga pada rate card Radio 99ers menyesuaikan dengan permintaan klien dan menyesuaikan dengan rating yang dimiliki 99ers. Karena ada 3 klien yang biasanya bekerja sama yaitu Perusahaan/agency, EO, dan mahasiswa. Jadi harga yang ditetapkan pada rate card menyesuaikan dari rating yang dimiliki 99ers. Harga yang tertera pada rate card sudah cukup standar dibandingkan dengan kompetitor lain, karena harga perbandingan dengan kompetitor lain juga tidak terlalu jauh kisaran 200-400ribu rupiah.

Promosi yang dilakukan oleh Radio 99ers 
adalah advertising, public relations, word of mouth, event dan sponsorship. Dari beberapa strategi promosi yang dilakukan 99ers selalu mencoba membuat promosi agar semakin banyak pula orang yang mengenal 99ers di kota Bandung ini terutama anak muda. Elemen bauran promosi yang paling efektif yaitu event dan sponsorship, karena dengan event yang dibuat oleh 99ers semakin banyak pengunjung maka 99ers akan semakin diketahui oleh orang banyak. Yaitu event rutin bulanan 99ers yang bernama 9coustic. Untuk mempertahankan rating top radio segmentasi anak muda tentu saja ada beberapa proses yang dilakukan, proses yang dilakukan oleh 99ers yaitu konsisten dengan program yang dibuat, membuat program yang tidak membosankan didengar, lalu selalu melihat data statistik pendengar setiap harinya melalui web, evaluasi dan meeting secara rutin.

Lokasi Radio 99ers yaitu di Jl. Ir. H. Djuanda 126B Bandung, Dago. Lokasi tersebut sudah cukup strategis karena Dago merupakan daerah populer di kota Bandung dan aksesnya mudah dijangkau. Jadi dengan lokasi kantor Radio 99ers saat ini sudah cukup strategis dan baik dalam pemilihan tempat. Partisipan yang berpengaruh untuk mempertahankan top rating radio segmentasi anak muda tentunya ada 2 peran yang sangat berpengaruh yaitu pendengar dan pengiklan. Keduanya sangat berhubungan erat dan keduanya harus dipenuhi keinginannya. Karena jumlah pendengar akan berpengaruh pada klien yang ingin memasang iklan, begitu pula pengiklan berpengaruh untuk finansial perusahaan. Hukum kausalitas atau sebab akibat. Bukti fisik yang dimiliki oleh Radio 99ers yaitu alat programming, mobil operasional, seragam, id card, company profile, dan kantor. Bukti fisik yang dimiliki oleh Radio 99ers sudah cukup lengkap untuk membuat konsumen percaya dan yakin kepada Radio 99ers.

Sebaiknya Radio 99ers bekerja sama dengan pihak AC Nielsen secara rutin setiap tahunnya karena agar mengetahui peringkat rating setiap tahunnya, karena hal tersebut akan bermanfaat untuk klien yang akan memasang iklan apabila melihat rating radio yang dimiliki oleh Radio 99ers. Radio 99ers sebaiknya menambah bauran promosi yang belum dilakukan yaitu seperti personal selling, sales promotion, dan direct marketing. Karena agar semakin dikenal lagi oleh orang banyak dan mempertahankan awareness masyarakat terhadap Radio 99ers.

Sebaiknya dokumen yang dimiliki oleh Radio 99ers disimpan dan dijaga sebaik mungkin karena apabila membutuhkan dokumen seperti data statistik dari AC Nielsen maka tidak perlu mencari-cari lagi. Melakukan evaluasi dan meeting rutin untuk membahas program, dan promosi yang akan dilakukan agar Radio 99ers akan lebih baik lagi dan dapat mempertahankan top rating radio segmentasi anak muda.

\section{DAFTAR PUSTAKA}

99ers. (2016). Ramadhan 99ers. Rabu, 16 November 2016 pukul 16:30

Adrian, P. (2000). The essence of servies marketing: pemasaran jasa. Yogyakarta: Andi Offset.

Bogdan, R. C.\& Biklen, S. K. (1982). Qualitative research for education: an introduction to theory and methods. Boston: Allyn and Bacon, Inc

Booms, B. \& Bitner, M. (1980). New management tools for the successful tourism. Manager of Tourism Research. 7(3):337-351

Bungin, B. (2013). Metodologi penelitian sosial \& ekonomi format-format kuantitatif dan kualitatif untuk studi sosiologi, kebijakan publik, komunikasi, manajemen, dan pemasaran. Jakarta: Kencana

Hamdani, L. (2006). Manajemen pemasaran jasa. Jakarta: Penerbit Salemba Empat

Kaelan. (2012). Metode penelitian kualitatif interdisipliner. Yogyakarta: Paradigma

Lubis, M. (2017). Radio masih memiliki tempat di hati pendengarnya. Diakses dari http:// www.nielsen.com/id/en/press-room/2016/ radio-masih-memiliki-tempat-di-hati pendengarnya.html

McColl-Kennedy, J. R., Daus, C. S., \& Sparks, B. A. (2003). The role of gender in reactions to service failure and recovery, Journal of Service Research, Vol. 6, No.1, pp. 66-82

Moleong, L. J. (2006). Metode penelitian kualitatif. Bandung: Rosdakarya

Nazir, M. (2005). Metode penelitian. Bogor: Ghalia Indonesia 
Patton, M. Q. (1980). Qualitative education methods. Beverly Hills: Sage Publication

Kotler, P. (1998). Dasar-dasar pemasaran $7 e$. Jakarta: Prentice Hall, Inc

Pramudiana, Y., dkk. (2015). Marketing plan bagaimana menganalisis dan menyusunnya. Bandung: Alfabeta

Putra, A. B., Yulianto, E., \& Sunarti. (2015). Pengaruh bauran pemasaran jasa terhadap keputusan pembelian. Jurnal Administrasi Bisnis (JAB) Vol 1, 1-8

Rachmawati, R. (2011). Peranan bauran pemasaran (marketing mix) terhadap peningkatan penjualan (sebuah kajian terhadap bisnis restoran). Jurnal Kompetensi Teknik Vol. 2, 143-150

Satori, D. \& Aan, K. (2011). Metodologi penelitian kualitatif. Bandung: Alfabeta

Selang, C. A. (2013). Bauran pemasaran (marketing mix) pengaruhnya terhadap loyalitas konsumen pada fresh mart bahu mall manado. Jurnal EMBA Vol 1, 71-80

Sugiyono. (2011). Metode penelitian kuantitatif, kualitatif, dan r\&d. Bandung: Alfabeta

Tjiptono, F. (2014). Pemasaran jasa. Yogyakarta: Andi Offset

Yanua, I. (2012). Metode penelitian sosial kualitatif. Bandung: Refika Aditama 